\title{
The Formation of Maritime Tourism (Yachting) Cluster as a Vehicle for Competitiveness Improvement: The Greek Case
}

\author{
Aggeliki Pardali ${ }^{1}$, Theodora Giantsi ${ }^{2, *}$ \\ ${ }^{1}$ Professor, Department of Maritime Studies, University of Piraeus, Piraeus 18534, Greece \\ ${ }^{2}$ Laboratory and Teaching Staff, Laboratory of Harbour Works, National Technical University of Athens, \\ Greece
}

*Corresponding Author: Theodora Giantsi, Laboratory and Teaching Staff, Laboratory of Harbour Works, National Technical University of Athens, Greece

\begin{abstract}
This paper presents an innovative organizational structuring of the Greek Marine Tourism Industry (yachting) that coordinates its main developmental core of marinas and ports with the regional economic forces and advantages, in the principles of sustainability and growth. The proposed model, leaning on the strategic formulation and governance of cluster for marinas, ports, private companies, independent associations and public and private institutions, directly and indirectly involved in the yachting tourism industry, would address and attract a competitive network of global investors and customers, greatly contributing to the country's overall economic expansion. This novel strategic focus on a multitude of cooperating companies, exploits the advantages in the conference of different individual business characters, guaranteeing long-term prosperity.
\end{abstract}

Further on, this paper investigates the prerequisites for the formation of an effective maritime tourism cluster (yachting) that will motivate competitiveness and extroversion, towards upward levels of employment and regional development.

Cluster main characteristics will be collected through bibliography: economic specialization and geographic concentration will be examined and reasons for establishment will be expanded on. All necessary characteristics for satisfying governance of maritime cluster will be collected and examined.

\section{INTRODUCTION}

Cluster is a concept that covers a wide range of various business structures dominated by geographic proximity. According to Porter (1990), industrial clusters are regionally concentrated, inter-linking companies and institutions within a specific field of action. Rosenfeld (1995) considers that these companies create together a comparative advantage benefitting not only themselves but the whole of the host economy. The geographic concentration of companies covered by the cluster is mainly determined by the geographic area in which the cooperation between companies / organizations is developed but does not exclude cooperation between companies / entities outside the business cluster. By adopting the De Langen (2003 and 2004) interpretation, we can define the business cluster as a population of business units, associations and private or public organizations (institutions), operating around a distinct economic specialization (in this case the maritime tourism) and characterized by their geographic concentration and their reciprocal relations.

In any case, the mutuality of relationships and the cooperation between the members of the cluster is the fundamental rationale behind the cluster's formation. These fundamental relationships can be either vertically connected cooperation or competitive correspondences within the business cluster (Ebbekink M., 2010). The aim of the cluster operation is to develop multiplying character synergies between the associate companies, so that the companies through collective actions achieve results that would be impossible to achieve independently (Porter M., 1998, Delgado, M. et al. 2010).

As it concerns Greece, the establishment of a maritime tourism cluster is expected to contribute at the economic expansion of the country (Pardali A., Miliaraki M., 2006), contributing to the promotion of the Greek islands, bringing revenue to the country, and creating jobs. (Chen et al., 2016) 


\section{The Cluster of MARitime Tourism (YACHTING)}

\subsection{The Population of the Cluster}

The population of the cluster consisted of enterprises, public and private bodies that are directly or indirectly involved in the basic economic specialization. Ships and passengers are looking for services in ports, so we can identify both direct and support enterprises involved in the specialization under investigation.

Services provided by the touristic ports (marinas) to ships and passengers are:

- Port services as mooring and anchorage, well traffic sign, berths protected from the weather, boat launching ramps, warehouses, parking areas, easy access to the hinterland, dry storage areas for repairs and winter storage, safety and security systems

- Commercial port services, as water supply, bunkering, marine equipment and food supply, restaurants, bars, electricity, modern communication systems, waste reception facilities, banking services, hygiene facilities and cleaning complexes (WC and shower, laundries, dry cleaning), commercial shops, health care centre, pharmacy

- Public services: customs, coast guard

- Repair services: including repair and maintenance units of the boats, technical support of electronic instruments, marine equipment \& supplies

- Tourist-cultural and other services such as information, tourist attractions, entertainment venues, sports facilities, museums, cultural events

These services can be provided by the port company or by other entities of the local community. As a result, all these companies, entities and organizations can formulate the population of the cluster under exploration (Pardali A., Sakelariadou F., 2000). Private and public entities such as the Ministries involved, the Chambers, the Professional Associations, the Educational Institutions, etc. should be added to this population.

\subsection{The Formation of the Cluster}

Although the creation of clusters has many advantages, their formation is neither automatic, nor can be performed ex nihilo (Muro and Katz, 2010). The establishment of a cluster requires a strong infrastructure of knowledge and an already functioning substratum of companies with entrenched and possible strong activity, the needed institutional structures and organizations (at local, regional and/or national level) and the appropriate support services. It also requires the existence of favorably predisposed investors, a business culture that emphasises openness and innovation and finally an established cooperation between businessmen and local authorities in a comprehensive developmental strategic framework (Gilsing V. et al., 2005).

\subsection{The Structure of the Cluster}

For the successful development of a business cluster, several structural elements are needed. Key factors defining the structure of a business cluster is the existence of agglomeration economies, sufficient internal competition, the absence of entry or exit barriers and the heterogeneity of population (Rosenfeld S., 2002). According to Krugman (1991), the agglomeration economies are considered in relevance to the local concentration of businesses, suppliers and skilled manpower. The latter gets attracted to the locality by the operations of the basic economic specialization (Pardali, et al., 2016).

\subsection{The Governance of the Cluster}

The concept of the governance of the cluster comprises the entity of the mechanisms needed to coordinate the activities of its members (De Langen, 2003). The aim of the cluster governance is to establish collective actions targeting at creating and maintaining the sustainable competitive advantage for the entire cluster. Parameters that affect the costs and therefore the success of cluster governance are: a climate of trust among stakeholders, the presence of leading companies, which, due to their size, market position, knowledge and business skills (Lorenzoni and Baden-fuller, 1995), have the inclination and ability to invest, the configuration and formulation of methods of collective 
action(through Associations, networks, cooperation of public and private actors) and finally the presence of intermediaries (businesses, consulting services or structures) that possess, collect and distribute the necessary information to members of the cluster (Pardali A., 2016).

In the case of maritime tourism cluster, these roles can be played by travel agencies, tour operators, maritime agency offices, research institutes, associations and chamber unions conducting field studies.

Currently, the existing structural model of Greek maritime tourism assigns the decision-making policy processes of local and regional level to national level. Several researchers noted (Pardali et al, 2007), though, that it is essential that a business cluster's policies and governance run bottoms-up, with the local authorities and stakeholders maintaining clear positions in the design and implementation processes of the cluster's strategies. Local authorities should be maintaining the roles of orchestra directors (Ebbekink, 2010) and coordinators of the development and sustainability processes (Lagendijk, 1999).

\section{GREEK YACHTING}

\subsection{The Institutional Framework}

The first law concerning the maritime tourism in Greece was Law 438/1976 "About Tourist ships and vessels and marine sports vessels and regulation of tariff and taxation matters on ships and on ships of pleasure".

Then, Law 2743/1999 "Recreational vessels and other provisions" filled the gap in the evolution of maritime tourism, distinguishing between private and business yachts in ownership and function and prohibiting the commercial leasing of private yachts.

Finally, Law 4256/2014 "Tourist vessels and other provisions" came to replace Law 2743/1999, as new fundamental Law ruling the market. Its key increasing competitiveness points in force today are:

- Private yachts may be leased commercially and commercial yachts may be used by private owners under specific conditions

- Foundation of the Electronic Registry and, in 2013, activation of the Tax for Residence and Voyages; the latter's collection has not begun yet, whilst new taxation is imposed

- Simplifications of arrival and departure procedures of yachts are energised

- Reduction of crew requirements

- Reduction of chartering requirements

- Strengthening of passenger safety measures

Recently, Law 4504/2017 tried to reactivate the Tax for Residence and Voyages, never activated in reality by Law 4256/2014 due to never publishing the necessary legal acts. This legal framework has taken forward steps in the right direction but both its skeletal widening and changes in mentality are needed for future development of the Greek maritime industry.

\subsection{The Supply}

\subsubsection{The Pleasure Boats and their Management Companies}

In Greece, information on both the types and the number of pleasure boats is unclear. According to ICOMIA 2013, the number of yachts in use is estimated at around 130,000. This number comprises sailboats, motorboats, inflatable boats, sport boats, recreational fishing boats et al. However, the purely commercial yachting is provided by yachts management companies and Shipping Companies for Recreational Boats (SCRB). The yachts management companies are centring in the managing of sailing boats by $70 \%$ and motorboats form the rest 30\% of business (Georgiadis - Minadaki, 2005).

It is a requirement to the shipping companies managing recreational boats that they get registered with the SCRB registry of the Ministry of Maritime Affairs and Insular Policy, because their vessels are typed as commercial/tourist, whereas tourist companies under different legal specification, e.g. Ltd LLC, S.A. e.c.t., do not have to register with the SCRB.

The official professional organizations/maritime navigation representatives in Greece, who play, according to Corres (2007), a serious role in forming policies, are: 
- Greek Professional Yacht Owners Bareboat Association

- Hellenic Professional Yacht Owners Association

- Hellenic Private Yacht Owners Association

- Hellenic Yacht Brokers Association

The total number of SCRB registered companies currently stands at 1,781, of which only 1,042 are active (700 in Attica). Of the remaining 739 companies, 119 (96 in Attica) are under dissolution and 620 (537 in Attica) under liquidation process. Regarding the number of ships, 1,216 are active vessels and 983 out of management, due to the dissolution and liquidation of the companies that managed them. Unfortunately, Ministry officials have pointed out that off-managed ships cannot be identified during this period. Actually, it is impracticable to impose these vessels on existing companies in their form of property/management/operation or in other foreign companies. As a result, they are reported as out of management.

\subsubsection{Location of Headquarters and Magnitude of Companies}

In Greece, there are 1,045 active SCRB companies, $75 \%$ of which are located in the prefecture of Attica. $77 \%$ of companies are in the process of liquidation and $88 \%$ of cleared companies are also located within the Attica prefecture. The majority of these companies hold 1-4 vessels, 19 companies hold 5-10 vessels, 4 companies hold 10-15 vessels and only one company owns over 25 vessels, confirming that this market is dominated by small and medium sized companies (figure1).

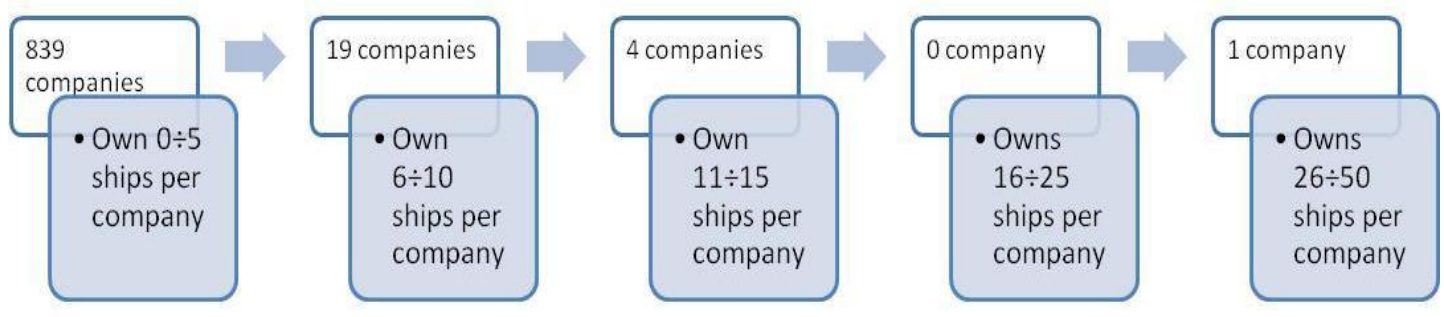

Figure1. Ships per SCRB Company

Source: Ministry of Maritime Affairs and Insular Policy, Registry forS.C.R.B, 2015

\section{TOURIST PORTS - MARINAS}

\subsection{The Institutional Framework}

In Greece, there are three categories of tourist ports: marinas, shelters and moorings. Facilities' requirements, dimensions' requirements and services for each category of tourist port are specified in the current legislation. Law 2160/1993, amended by a sequence of subsequent laws such as Law $4329 / 2013$, regulates the spatial planning and licensing of tourist ports. The tourist ports are under the Ministry of Tourism, whereas all other Greek ports are under the Ministry of Shipping (Pardali A., Giantsi T., 2015).

Greek government policies regarding tourist ports recently focused on:

- The privatization of tourist ports through the Hellenic Asset Development Fund (HADF)

- The creation of new berths by exploiting the existing facilities

- The reduction of the licensing time

Also, significant effort for the liberalization of the market was made by bringing forward a plethora of laws. Key changes in the legal framework concerning tourist ports during the last years regard:

- The spatial planning process of the tourist ports

- The simplification of the licensing and operating procedures of the tourist ports

- The facilitation of the licensing of buildings

- The permission of berthing of yachts in existing tourist ports and the dolphin enactment, although the conditions of their operation have not been determined 
Currently, the big majority of Greek tourist ports (most of them not operating), managed by public entities (Greek Tourism Organization, Port Authorities, Port Funds), as well as the ports managed by port authorities, are under the Hellenic Asset Development Fund (H.A.D.F.), awaiting privatization. The unclear bureaucratic status, lack of further defining regulation, poor marketing and political uncertainty are causing stagnation in the infrastructure development of tourist ports.

\subsection{The supply}

According to data supplied by the Greek Tourism Organization there are 54 marinas, 73 shelters and 22 moorings officially spaced to date. Of these, 28 marinas are operating or semi-operating, 22 of which have formed the Greek Marinas Association, with a capacity of 8,497 berths. 7 of these are located in the Attica region, covering the $40 \%$ of the overall capacity (figure 2 and 3 ).

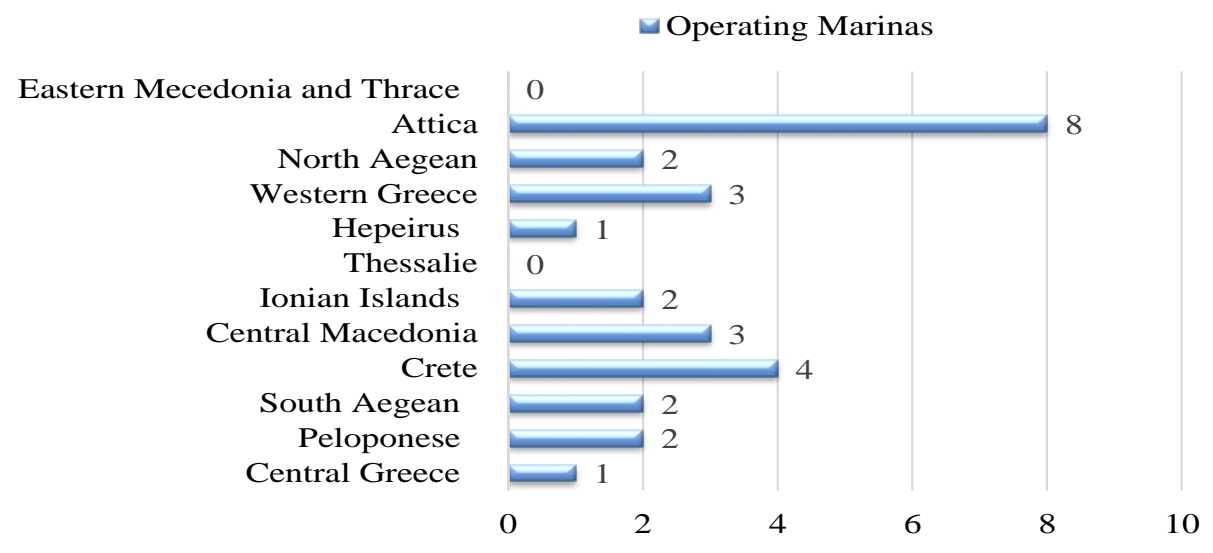

Figure2. Operating Marinas per Greek region

Source: Data from Ministry of Tourism (2016), personal analysis

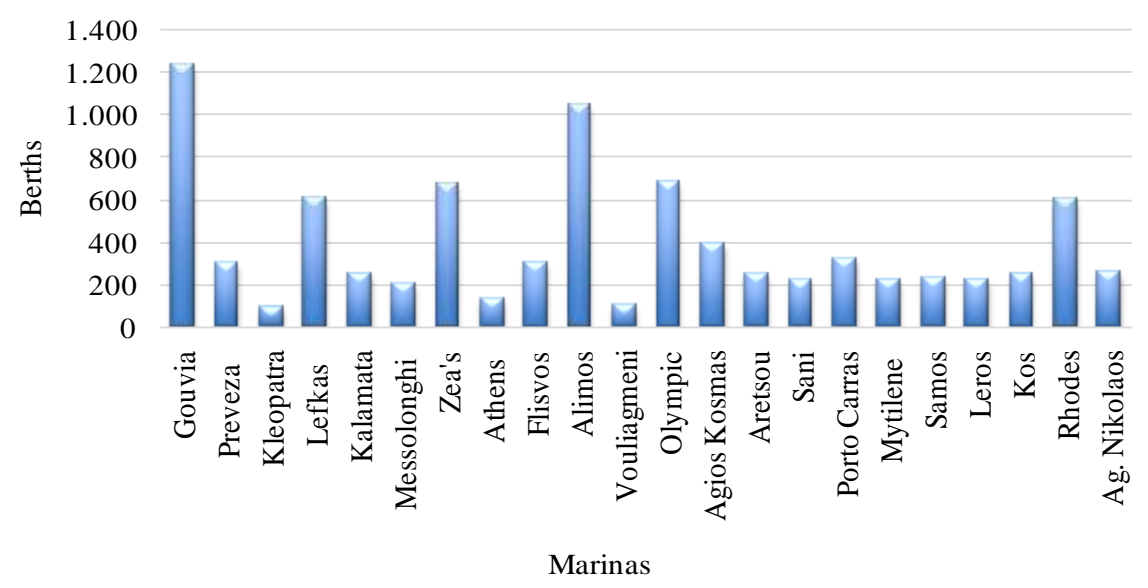

Figure3. Berths per Marina

Source: Greek Marinas Association, 2015

It is obvious that Gouvia Marina holds the most berths, followed by the Alimos Marina, the Olympic Marina, the Marina Zeas, the Marina of Rhodes and the Marina of Lefkas.

Most coastal passenger ports of the country also offer berths to the yachts; the number of berths stands approximately at 4,180 .

Most marinas are public but managed by private corporations. Today 18 operating Marinas are managed by private companies, 4 by municipalities, 4 by Port Funds and 2 by H.A.D.F., according to Ministry of Tourism. Important data: about $63 \%$ of the Greek Marina capacity is managed by three companies, ( $38 \%$ by one company, $17 \%$ by a second company and $8 \%$ by a third one), which leads us to conclude that a market concentration is under development. 
The Formation of Maritime Tourism (Yachting) Cluster as a Vehicle for Competitiveness Improvement: The Greek Case

\section{InVestigation on the Conditions' Existence for the DeVelopment of Marine TOURIST CLUSTER}

\subsection{Research Methodology}

The geographic concentration of the specific economic specialization in Piraeus was sourced from the location of shipping companies' components, obtained by the Ministry of Maritime Affairs and Insular Policy. The composed structured questionnaire is based on the given geographic concentration of shipping companies SCRB and tourist ports (marinas) in the wider region of Attica and on the cluster theory. The questionnaire's main target was to investigate the conditions for the existence of those elements leading to the development and establishment of a competitive marine tourism cluster.

\subsection{The Analysis}

The analysis of questions and answers to the questionnaire was divided into groups. The first group of questions was related to the identification of geographic concentration and its benefits.

The second group was related to the identification of mutual responses between the stakeholders and the intensity of these, as well as the awareness of the participants that they belong to a particular economic specialization.

The third group of questions aimed to identify the specific elements in the economic expertise structure, leading to the organization of a competitive cluster. A final group of questions addressed the governance issues of the cluster under consideration.

The Attica area's attraction points for the establishment of the stakeholders were, for approximately: $41 \%$ the proximity to the customer basis, $25 \%$ the proximity to the partnering market, $13 \%$ the proximity to the suppliers, $9 \%$ the proximity to leading enterprise and $6 \%$ the availability of skilled labour (figure 4).

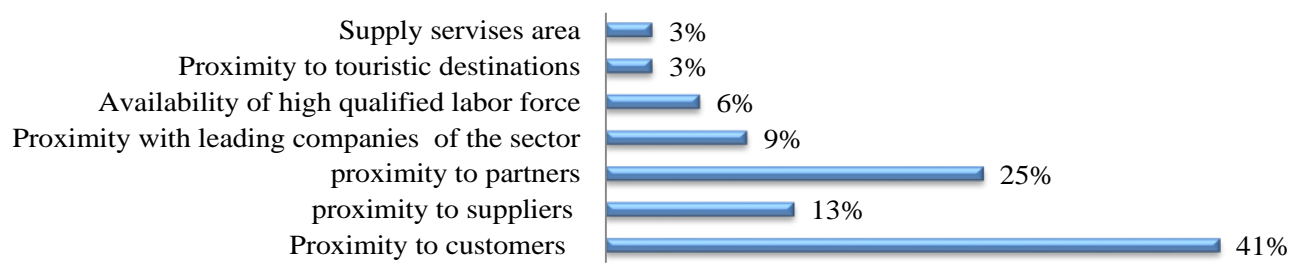

Figure4. The reasons for the establishment of companies in the Attica area

Source: Questionnaire

Figure 5 displays the pattern of the respondents' answers regarding the enterprising advantages of the Attica area. Important advantages are, for approximately: $86 \%$ the proximity to major customers, $71 \%$ the availability of market information, $67 \%$ the availability of high qualified labourforce, $67 \%$ competitor existence, $57 \%$ the proximity to specialized suppliers etc.

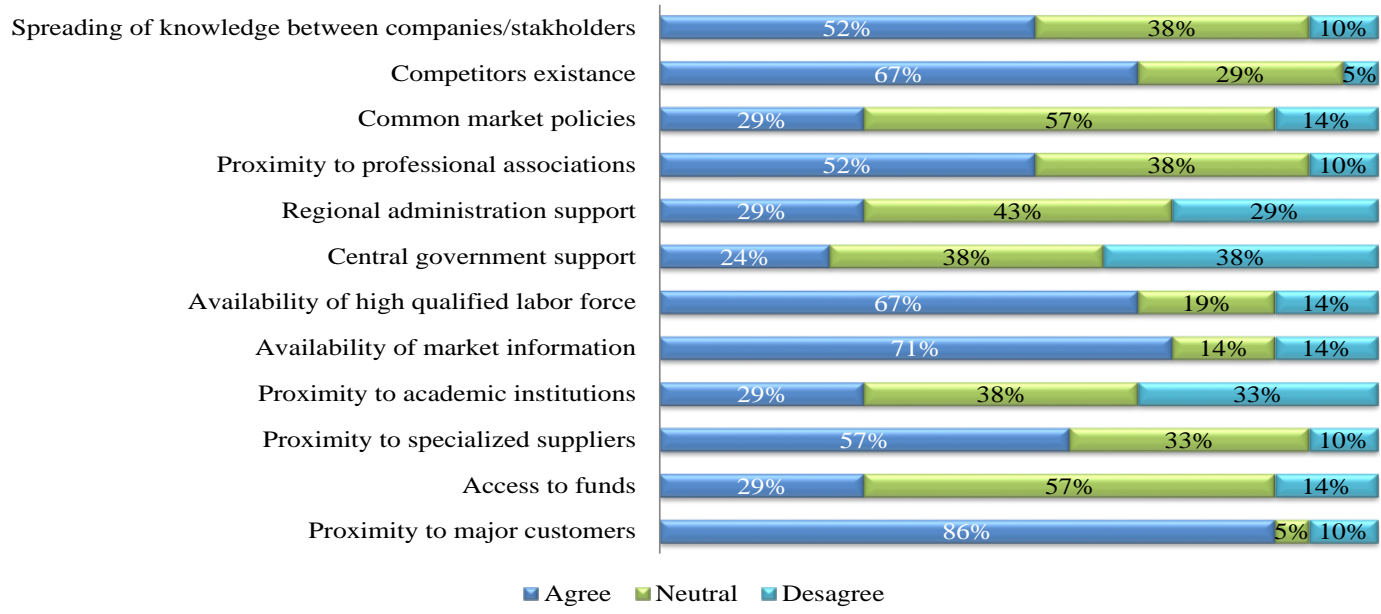

Figure5. The company's installation in the specific area ensures the following advantages

Source: Questionnaire

International Journal of Research in Tourism and Hospitality (IJRTH) 
From the answers to the question "how do you register the intensity of your company/ organization's relations with the following enterprises", we observe that there are strong relations between most branches, especially between repair companies (86\%), commercial companies (71\%) and bunkering companies $(67 \%)$. There are less strong relations with financial institutions (29\%), land transport companies (29\%) and consulting firms (24\%) (figure 6).

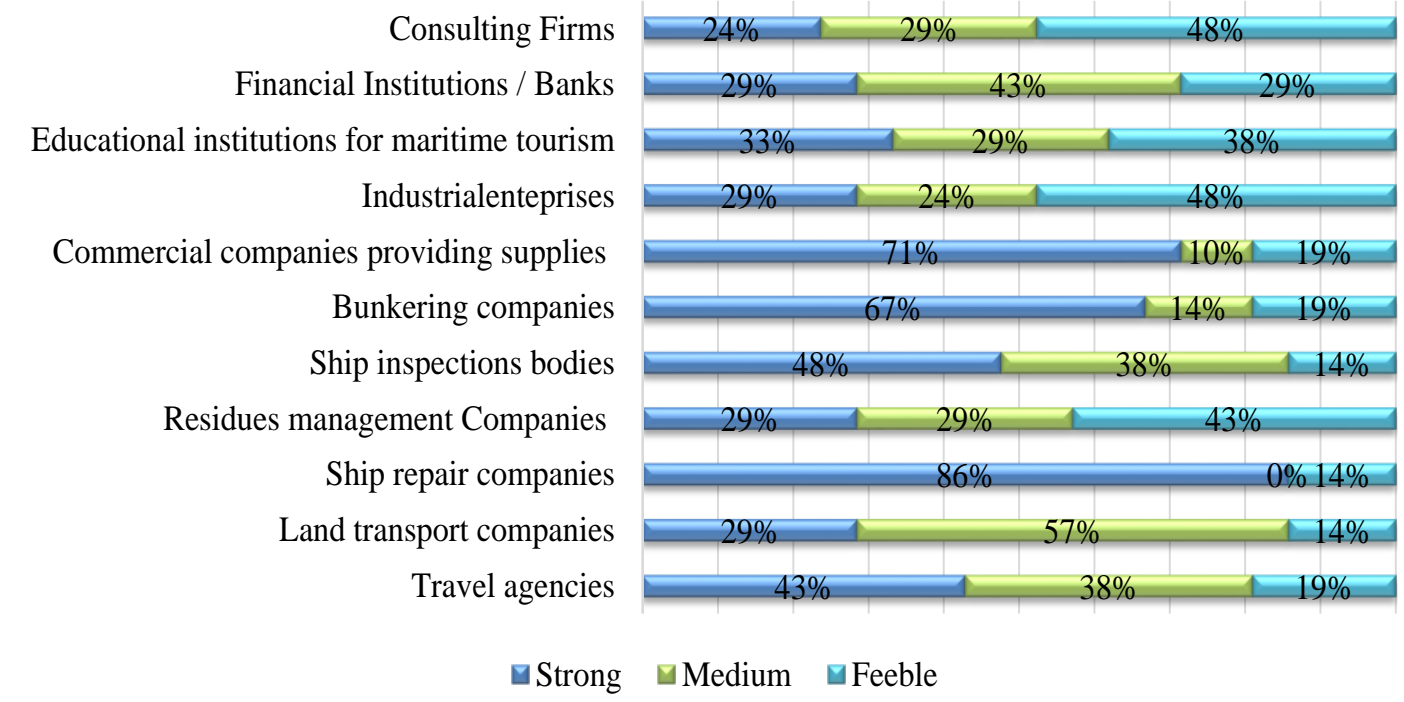

Figure6. The tension of relations between enterprises in the cluster under consideration

Source: Questionnaire

The aim of the question "provide your degree of agreement with the proposals below" was to identify the dominant pole of economic specialization, as well as the sense of belonging to the same group. We observe that the $86 \%$ of the respondents feel that they are part of the economic specialization. The $52 \%$ consider as a dominant pole of specialization the yachts and $52 \%$ consider as a dominant pole of specialization the marinas. The $81 \%$ think that the economic specialization is dominated by small and medium sized enterprises (figure 7).

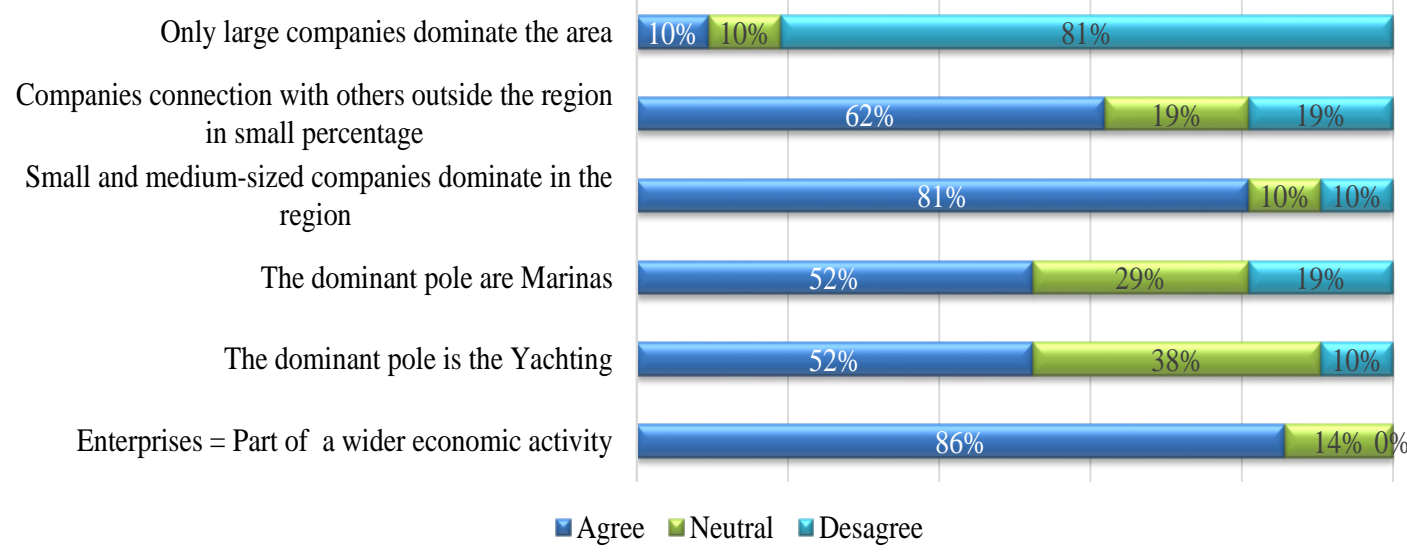

Figure7. The degrees of agreement with specific proposals

Source Questionnaire

To the question, "how do you believe that the following suggestions will improve the competitiveness of economic specialization", we observe that about $81 \%$ of the respondents believe, by the improvement of the knowledge, $81 \%$ the development of common values, $81 \%$ the emphasis on innovation, $76 \%$ the exploitation of the existing knowledge, $76 \%$ the informal communication with customers and suppliers, $67 \%$ more cooperation with other companies, and finally 52\% focusing on talent detection, shall contribute a lot to the increase of competitiveness. (figure 8). 
The Formation of Maritime Tourism (Yachting) Cluster as a Vehicle for Competitiveness Improvement: The Greek Case

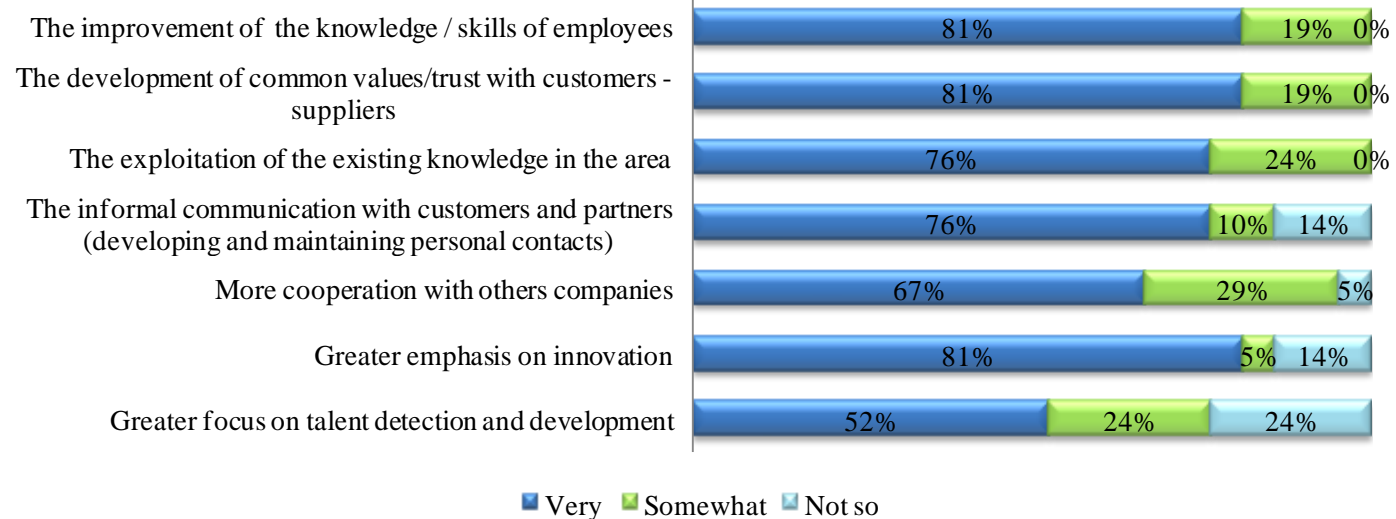

Figure8. Suggestions for improvement of industry competitiveness

Source: Questionnaire

To the question, if the competition amongst companies based in the Attica area contributes to the increase of their overall competitiveness, $85 \%$ of the respondents answered positively. To the question, if the competition between companies keeps companies alert and encourages innovation, $81 \%$ of the respondents answered affirmatively. It is therefore clear that internal competition exists and contributes to keeping companies alert and to the introduction of innovation. Also, $69 \%$ of the respondents think that competition pushes towards expanding into other markets. These requirements provide the industry with extroversion.

Finally, with regard to entry/exit barriers, the respondents, by $69 \%$, replied that it is easy to set up new companies in the considered area and 58\% agreed that it is difficult to relocate outside the Attica area. Respondents have largely accepted that there are entry/exit barriers to the market. From the above analysis it is evident that to a significant degree there already are the conditions of structure for the development of a cluster in the specific economic specialization.

Concerning the question "what policies/initiatives are considered important for improving the competitive position of yachting in the area under consideration", $92 \%$ believe that, the institutional framework, which restricts competition, should be modernized, $88 \%$ that integrated services should be provided through partnerships with other companies, $77 \%$ that emphasis should be placed on knowledge and training, $77 \%$ that emphasis should be placed on the promotion of new careers in the industry, $73 \%$ that the cooperation between enterprises and other stakeholders should increase, $69 \%$ that the effectiveness of professional associations should increase, $58 \%$ that the concentrating all of the yachting stakeholders in a park, 54\% that the Public relations and lobbying for the industry are necessary, and 54\% that bureaucratic practices should be reduced, etc. (figure 9).

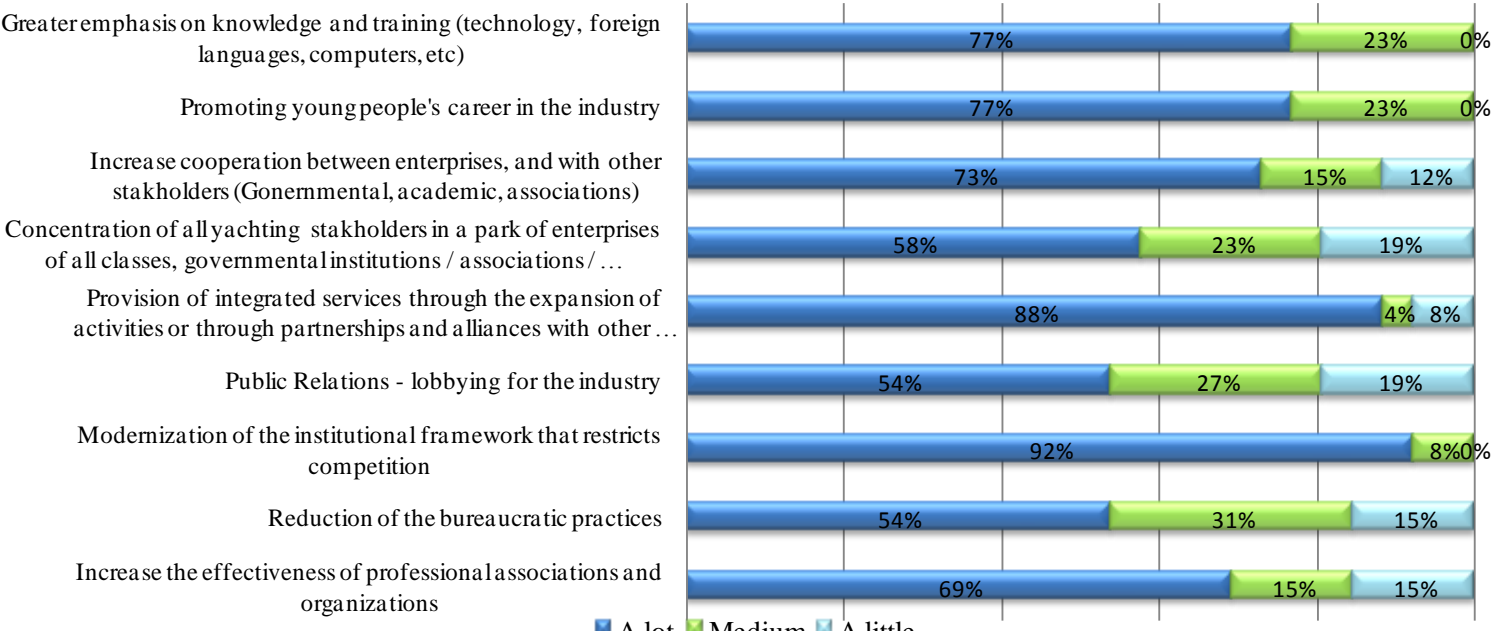

$\square$ A lot $\square$ Medium $\square$ A little

Figure9. The initiatives that will contribute to increase of competitiveness

Source: Questionnaire

International Journal of Research in Tourism and Hospitality (IJRTH) 
On questions regarding the institutionalization and the governance of the underdevelopment cluster, $90 \%$ of the respondents replied that they agreed that the establishment of a maritime tourism cluster would contribute to increasing competitiveness and that they are willing to participate in it. Concerning the governance of the cluster, $62 \%$ of the respondents proposed that an independent authority represented all stakeholders, $24 \%$ identified this authority with the Ministry of Tourism, $9.5 \%$ proposed as authority one of the leading enterprises in the sector and $5 \%$ proposed the authority of a combined public-private sector (Figure 10).

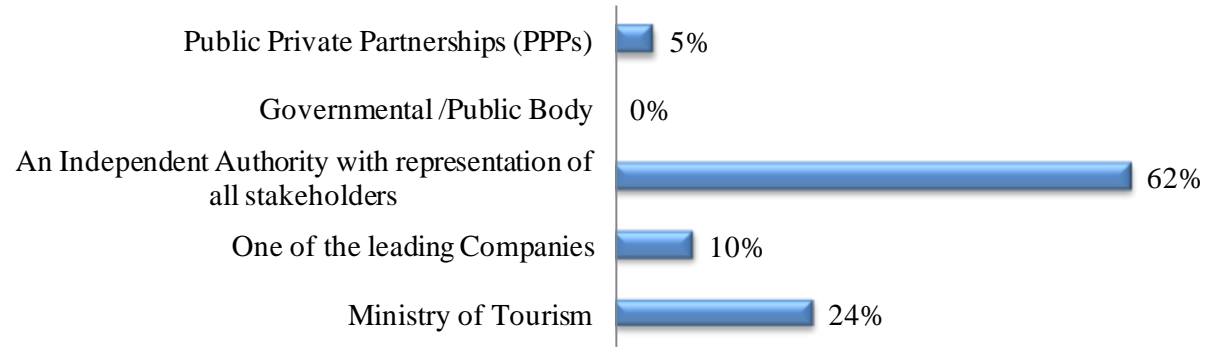

Figure10. The cluster's coordinator

Source: Questionnaire

\section{CONClusions}

Maritime tourism in Greece, despite the efforts made in recent years, has yet to overcome its inherent problems. Its status seems to be the result of a malfunction, both within the organizing strategy and the management / governance framework in planning, design, decision-making and implementation. Despite the fact that steps have been taken to reform the relevant legal framework and institutional interventions have been made via the structuring of strategic public-private partnerships to generate more flexible administration, the dynamic of the Greek maritime tourism market remains untapped.

The establishment and governance of a business yachting cluster in Greece based on the yachting companies, marinas and ports of each region, also including the supporting industries and stakeholders, can create a competitive complex with global appeal.

The multiple effects resulting from the development of a business cluster in maritime tourism (yachting) are expected to be diffused into the hinterland and will contribute to the development of the region. Each region shall have the ability to produce full package products of maritime tourism with the prospect of competitiveness at the global level.

The key factor for organizing a business cluster is geographic concentration. This is strong in the region of Attica and particularly in Piraeus, both for the yachting companies and for many of the supporting industries. $41 \%$ of the respondents of the questionnaire answered that the installation in Attica is primarily associated with the proximity to customers, partners and suppliers, a fact which confirms the reciprocal relations between customers and vendors, necessary elements for the organization of a business cluster.

On the question about the advantages of the region, a large percentage of respondents consider very significant the proximity to important clients, the availability of information on the market, the availability of qualified personnel, the activation of competitors etc.

Regarding the intensity of relationships between enterprises-entities of economic specialization and supporting enterprises-entities, we observe that there is a strong correlation between mainly trade and repair businesses and less powerful interaction with financial and educational institutions.

Overall, $86 \%$ of respondents feel that they belong to the same group (economic specialization) and believe that this is dominated by small and medium-size enterprises.

$76 \%$ of the respondents agreed that informal communication with customers and suppliers and the development and maintenance of interpersonal contacts contribute to the improvement of competitiveness; the same percentage believes that greater emphasis on innovation will help increase competitiveness. $77 \%$ believe that the exploitation of existing knowledge in the area, the development of shared values of trust between suppliers-customers and the greater focus on detection and development of local talent would contribute greatly towards the same direction. 
$85 \%$ of respondents think that competition among enterprises contributes to increasing competitiveness and $81 \%$ think that competition fosters innovation. Respondents largely accepted that there are barriers to entry-exit in the market (a negative factor in the cluster).

Initiatives that would contribute primarily to increasing the competitiveness of maritime tourism are: the reduction in bureaucracy, the modernization of the institutional framework, the greater emphasis on knowledge and training, and the increase of cooperation between enterprises.

Finally, the vast majority of respondents agreed to participate in the formation of a business cluster. $62 \%$ proposed that the governance was undertaken by an independent body with representatives from all stakeholders, 24\% suggested that the consultation was undertaken by the Ministry of Tourism, $10 \%$ that a leader company should step in and 5\% that it should be run by a public-private sector partnership.

The concentration of industry in Attica, as well as all the elements of the structure and the governance of a competitive cluster, seem to coexist in the region to a considerable degree. Aiming at the establishment of the cluster, the selection of a common vision and a common strategy for those involved, as well as public consultation and a sequence of necessary steps are required for the achievement of the goal.

A first step would be the beginning of a public consultation on the establishment and the setting up of the business maritime tourism cluster (yachting). A second would be the choice of agreed vision and a third step would be the definition of strategies to follow through.

Several marked requirements to be kept note of on the course of achieving increased competitiveness of the maritime tourism and supporting industries are:

- Data collection (recording vessels, companies, institutions etc.) for the industry and stakeholders

- Institutional and regulatory framework able to facilitate the competition and to comply with the environmental needs and safety issues

- Compatibility of the institutional framework with those of other European countries, in active participation to shape common public policy

- Incentives to attract Greek people in tourist yachting product of maritime tourism

- Introduction of new products, safe to users but innovatively attractive

- Attracting of international (leading) regattas, development of interarea sea sports / games

- Targeted actions for the development of yachting in maritime routes

- Development of maritime sports and training facilities on sports (sailing, water skiing, boating)

- Development of local communities by providing services in this area (food markets, restaurants, archaeological sites, art galleries, retail outlets, etc)

- Development, organization and operation of tourist ports as a network of marinas and shelters, to provide full services to private pleasure boats and to companies

- Specialization of tourist ports based on served boats' categories

- Attracting investors for the exploitation of existing infrastructure

- Absorption of European Community development funds

- Waterways network

- Use of new technologies on reservations, marina management and chartering system

- Emphasis on developing shipyards and repair units, for greater added value

\section{REFERENCES}

[1] Chen J. M., Balomenou C., Nijkamp P., Poulaki P. and Lagos D., (2016), The Sustainability of Yachting Tourism: A Case Study on Greece, International Journal of Research in Tourism and Hospitality (IJRTH),. Volume 2, Issue 2, 2016, PP 42-49, dx.doi.org/10.20431/2455-0043.0202005.

[2] Corres, A.K. (2007), Greek maritime policy and the discreet role of ship owners' associations. In A.A. Pallis (ed.), Maritime Transport: The Greek Paradigm Research in Transportation Economics, 21, 221255. doi:10.1016/S0739-8859(07)21007-8. 
The Formation of Maritime Tourism (Yachting) Cluster as a Vehicle for Competitiveness Improvement: The Greek Case

[3] De Langen P.W., (2004), The performance of Port Clusters, Journal of international logisticsand trade, Vol. 2, no 1, pp. 47-56.

[4] De Langen P.W., (2003), The Performance of Seaport Cluster PhD dissertation Erasmus University, Rotterdam.

[5] Delgado, M., Porter, M. and Stern, S., (2010), Clusters and Entrepreneurship, Journal of Economic Geography, Volume 10, pp. 495-51.

[6] Ebbekink M., (2010), What's next in researching cluster policy: Cluster governance for effective cluster policy, Regional Studies Association 2009 Annual Conference, Pécs, Hungary, 25-05-10.

[7] Fromhold, M., and Eisebith, G., (2005), How to institutionalize innovative clusters? Comparing explicit top-down and implicit bottom-up approaches, Volume 34 1250-1268.

[8] Gilsing V., (2000), Cluster Governance, How clusters can adapt and renew over time, DRUID PhDconference, Copenhagen, January 2000.

[9] ICOMIA, (2013), Recreational Boating Industry Statistics book.

[10] Krugman, P., (1991), Increasing returns and economic geography, Journal of Political Economy, Volume 99 (3), pp. 483-99.

[11] Lagendijk, A. (1999), Regional anchoring and modernization strategies in non-core regions: Evidence from the UK and Germany. European Planning Studies, 00007(00006): 775-793.

[12] Lagendijk, A., (2002), Learning in Non-core Regions: Towards ,Intelligent Clusters'; Addressing Business and Regional Needs. In: Boekema, F., Morgan, K., Bakkers, S. and Rutten, R. (Eds.) Knowledge, Innovation and Economic Growth. Edward Elgar, Cheltenham, pp. 165-191.

[13] Lorenzoni, G., Baden-Fuller C., (1995), Creating a Strategic Center to Manage a Web of Partners, California Management Review, Vol. 37 No. 3, pp. 146,-163) DOI: 10.2307/41165803.

[14] Muro, M., Katz, B., (09/2010), The new "cluster moment": How regional innovation clusters can Foster the next economy, Metropolitan Policy Program at Brookings.

[15] Pardali, A. and Sakellariadou F., (2000), "Economic and environmental impacts from the operation of marinas: the Greek case", Marine Engineering and Ports. Southampton: WIT PRESS.

[16] Pardali A., Miliaraki M., (2006), Marinas as Poles for Sustainable Local Tourist Development, Archive of Economic History, XVIII, PP.10-26.

[17] Pardali, A., Stathopoulou, K., Thalassinos, Th., (2007), A cluster - based analysis for sustainable marine tourism development in Greece, 47th Congress of the European Regional Science Association, Paris August 29th-September 2nd.

[18] Pardali A., Giantsi T., (2015), Institutional Legal Modernization in Marine Tourism (Yachting) and Impacts in the Market, Conference Paper, September. (in Greek)

[19] Pardali A., Kounoupas E., Lainos I., (2016), Can cluster be bi-polar? Exploring the case of the Piraeus Port - Maritime Cluster, Maritime Policy and Management, April 2016.

[20] Porter M. E., (1990), The competitive advantage of nations (London: Macmillan).

[21] Porter M., (1998), Clusters and the New Economics of Competition, Harvard Business Review.

[22] Rosenfeld S., (1995), Over achievers: Business Clusters that Work: Prospects for Regional Development, Chapel Hill, N.C: Regional Technology Strategies, Inc.

[23] Rosenfeld, S. A., (2002), Creating Smart Systems: A guide to cluster strategies in less favoured regions, European Union-Regional Innovation Strategies, April 2002, Regional Technology Strategies.

Citation: Aggeliki Pardali, Theodora Giantsi. "The Formation of Maritime Tourism (Yachting) Cluster as a Vehicle for Competitiveness Improvement: The Greek Case". International Journal of Research in Tourism and Hospitality (IJRTH), vol 4, no. 1, 2018, pp. 64-74. doi:http://dx.doi.org/10.20431/2455-0043.0401008.

Copyright: () 2018 Authors. This is an open-access article distributed under the terms of the Creative Commons Attribution License, which permits unrestricted use, distribution, and reproduction in any medium, provided the original author and source are credited. 